\title{
Corrigendum: Identification of Cerebral Metal Ion Imbalance in the Brain of Ageing Octodon degus
}

\author{
Nady Braidy ${ }^{1}$, Anne Poljak ${ }^{1,2,3}$, Chris Marjo ${ }^{2}$, Helen Rutlidge ${ }^{2}$, Anne Rich ${ }^{2}$, \\ Bat-Erdene Jugder ${ }^{4}$, Tharusha Jayasena ${ }^{1}$, Nibaldo C. Inestrosa ${ }^{1,5}$ and \\ Perminder S. Sachdev ${ }^{1,6 *}$ \\ ${ }^{1}$ Centre for Healthy Brain Ageing, School of Psychiatry, Faculty of Medicine, University of New South Wales, Sydney, NSW, \\ Australia, ${ }^{2}$ Mark Wainwright Analytical Centre, University of New South Wales, Sydney, NSW, Australia, ${ }^{3}$ School of Medical \\ Sciences, Faculty of Medicine, University of New South Wales, Sydney, NSW, Australia, ${ }^{4}$ School of Biotechnology and \\ Biomolecular Sciences, Faculty of Science, University of New South Wales, Sydney, NSW, Australia, ${ }^{5}$ Centre for Ageing and \\ Regeneration, Faculty of Biological Sciences, Pontifical Catholic University of Chile, Santiago, Chile, ${ }^{6}$ Neuropsychiatric \\ Institute, Euroa Centre, Prince of Wales Hospital, Sydney, NSW, Australia
}

Keywords: LA-ICPMS, metals, Alzheimer's disease, bioimaging, Octodon degus

\section{A corrigendum on}

Identification of Cerebral Metal Ion Imbalance in the Brain of Aging Octodon degus by Braidy, N., Poljak, A., Marjo, C., Rutlidge, H., Rich, A., Jugder, B.-E. (2017). Front. Aging Neurosci. 9:66. doi: 10.3389/fnagi.2017.00066

OPEN ACCESS

Edited and reviewed by: Agustin Ibanez, Institute of Cognitive and Translational Neuroscience, Argentina

*Correspondence: Perminder S. Sachdev p.sachdev@unsw.edu.au

Received: 19 April 2017 Accepted: 21 April 2017 Published: 15 May 2017

Citation:

Braidy N, Poljak A, Marjo C Rutlidge $H$, Rich A, Jugder B-E,

Jayasena $T$, Inestrosa NC and Sachdev PS (2017) Corrigendum: Identification of Cerebral Metal Ion Imbalance in the Brain of Ageing Octodon degus.

Front. Aging Neurosci. 9:134. doi: 10.3389/fnagi.2017.00134
Due to a misunderstanding, the $O$. degus brain specimen used in the study were obtained from the animal facility of the Pontificia Universidad Catholic University of Chile, not the animal facility of the University of Valparaiso as previously stated in the article.

Therefore, in the animal methods section, the correct paragraph should read:

Octodon degus were obtained from a breeding colony at the animal facility of the Pontifical Catholic University of Chile and maintained in a controlled temperature room $\left(23 \pm 1{ }^{\circ} \mathrm{C}\right)$, under a 12:12 h light/dark cycle, with water and food provided ad libitum. At the time of this study, 16 male $O$. degus were grouped by age, from 12 to 36 months of age ( $n=8$ per group). Ages were selected to represent the development of AD-like pathology (36 months). All efforts were made to minimize animal discomfort and stress while also limiting the number of animals used. Aged animals were anesthetized with Equitesin ( $2.5 \mathrm{ml} / \mathrm{kg}$, i.p.) and injected with heparin (4 USP $/ \mathrm{kg}$, i.p.). Afterward, brains were surgically removed from their skulls and frozen in isopentane at $-78.5^{\circ} \mathrm{C}$. All procedures were conducted according to animal protocols approved by the Institutional Animal Care and Use Committee at the Pontifical Catholic University of Chile.

Conflict of Interest Statement: The authors declare that the research was conducted in the absence of any commercial or financial relationships that could be construed as a potential conflict of interest.

Copyright (c) 2017 Braidy, Poljak, Marjo, Rutlidge, Rich, Jugder, Jayasena, Inestrosa and Sachdev. This is an open-access article distributed under the terms of the Creative Commons Attribution License (CC BY). The use, distribution or reproduction in other forums is permitted, provided the original author(s) or licensor are credited and that the original publication in this journal is cited, in accordance with accepted academic practice. No use, distribution or reproduction is permitted which does not comply with these terms. 